\title{
We Live Again!
}

\section{By Elizabeth Cruickshank}

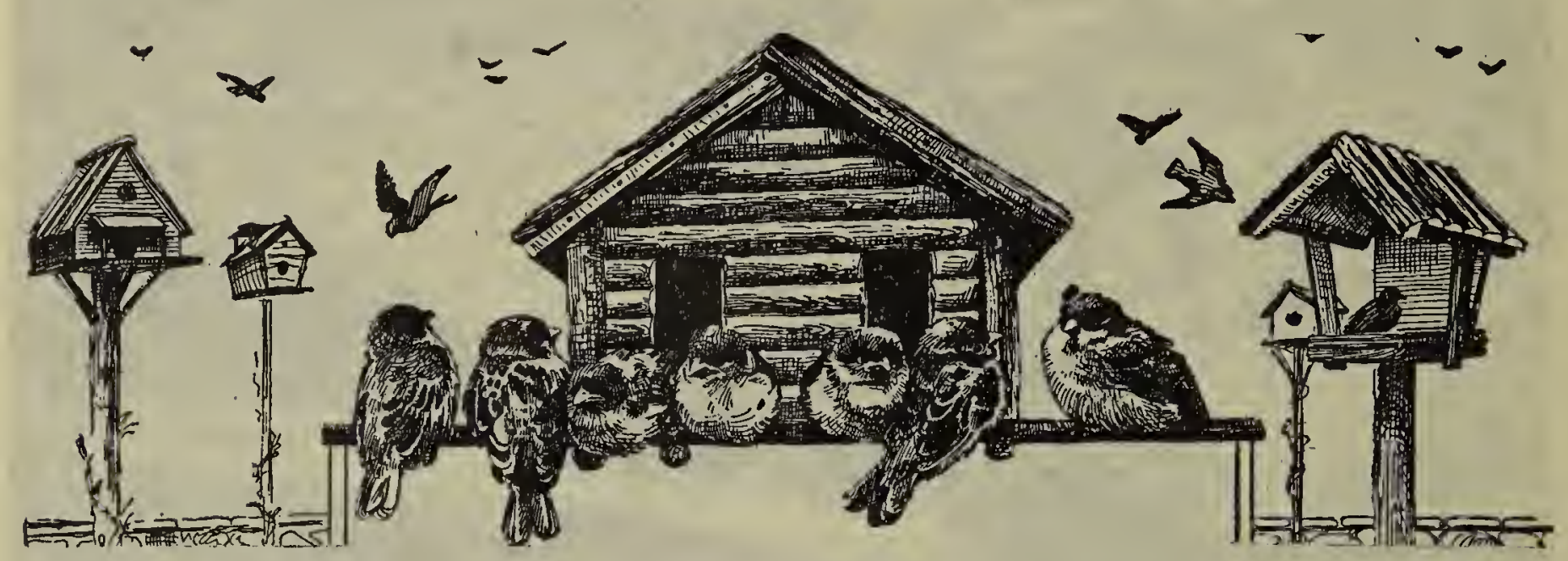

To waken to a snow-shrouded landscape early on a May morning was a disconcerting experience. The maple at our window-yesterday gayly decked in new green tassels-was still and beautiful in surprise.

Concerned for the birds, the new arrivals, I hurried pantrywards when I heard the new day welcomed with a sudden rush of song: the early greeting of a feathered optimist, the song that had lightened so many days of my life. No breakfast in sight, yet the robin had joy to share. From his merry heart, in the cool freshness of the morning, came forth a song to cheer and give wings to a nother heart. Cheer up, meet adversity with a song was his philosophy, for "out of winter is born the SPRING."

There was no adversity felt in the valley a few days later. Every slough, blue in the sunshine, was crowded with ducks and grebes. Wascana creek was hurrying riverwards from "haunts of coot and tern," green feathery tops of willows casting intriguing shadows and hiding nurseries for feathered folk in every quiet bend Sudden little gurgling falls over poplar poles, newly felled by the beaver, busy nearby, provided just the right background music. A dead old elm above was now a dormitory for a clan of noisy starlings. Tule grass and water fern seemed such a vivid green where water bugs, like glittering jewels, dashed and darted as swallows skimmed the glassy surface.

On the banks where wind and water-borne seeds had found lodging, festocns of tiny leaves garnished the moist brown earth. Early blue violets hid the grass. On the bare hillside hid in the grass. On the bare hillside paled by the brilliant gold of early cinqfoil. A miniature landslide had left craters made beautiful by missouri vetch's purple bloom.

With robins, orioles and yellow warblers singing-chipping, clay coloured, vesper and white throat sparrows all a part of the chorus "with every motion which they made it seemed a thrill of pleasure"-how could they help but sing! In the words of the cld proverb "Only those who have never felt the coldness of winter find no joy in the beauty of Spring."

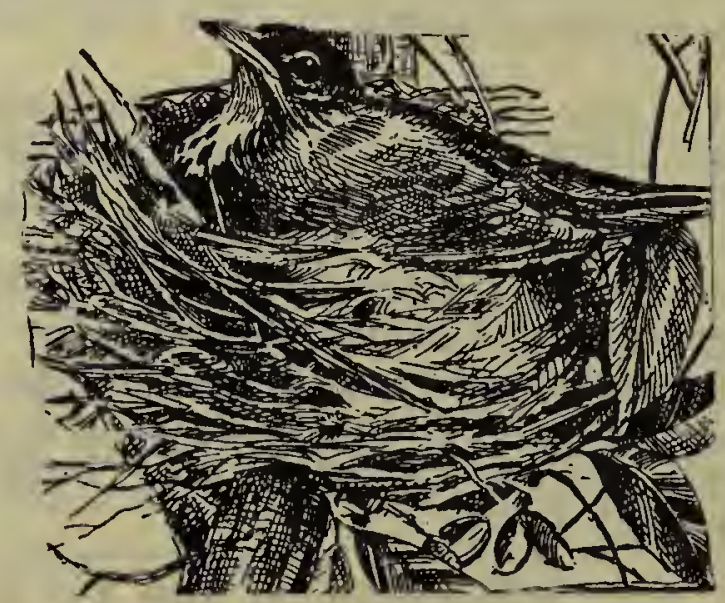

